\title{
4-aminopyridine restores visual ocular motor function in upbeat nystagmus
}

\author{
S Glasauer, R Kalla, U Büttner, M Strupp, T Brandt
}

J Neurol Neurosurg Psychiatry 2005;76:451-453. doi: 10.1136/jnnp.2004.045716

The effect of the potassium channel blocker 4-aminopyridine (4-AP) on spontaneous upbeat nystagmus (UBN) was investigated with the search coil technique during fixation in different gaze positions and smooth pursuit in a patient before and after ingestion of $10 \mathrm{mg} \mathrm{4-AP.} \mathrm{UBN} \mathrm{was} \mathrm{reduced}$ from $8.6 \mathrm{deg} / \mathrm{s}$ to $2.0 \mathrm{deg} / \mathrm{s}$ by $4-A P$ causing subjective relief from distressing oscillopsia, and impaired upward smooth pursuit was restored (gains: before medication 0.38; after medication 0.86). In the dark, UBN was slightly stronger and not affected by 4-AP. We propose that 4-AP improved the function of cerebellar pathways that mediate gaze holding and smooth pursuit by intensifying the excitability of cerebellar Purkinje cells.

$\mathrm{S}$ pontaneous upbeat nystagmus (UBN) - that is, upbeat nystagmus with gaze straight ahead, is an ocular motor disorder which manifests with oscillopsia due to retinal slip of the visual scene and postural instability. UBN usually increases with upgaze ${ }^{1}$ and is associated with impaired upward pursuit. ${ }^{2}$ It can be caused by lesions at several separate and distinct sites such as the pontomesencephalic junction, ${ }^{1}$ medulla, ${ }^{2-5}$ perihypoglossal nuclei, ${ }^{6}$ anterior cerebellar vermis, ${ }^{7}$ ventral tegmentum, ${ }^{8}$ and brachium conjunctivum. ${ }^{9}$ Lesions in the pathways mediating upward eye movements-for example, from the vestibular nuclei through the brachium conjunctivum to the ocular motor nuclei, might result in slow downward drift of the eyes that is repeatedly corrected by fast movements in the reverse direction. Although its causative mechanism is still not known, UBN is hypothesised to reflect an imbalance of vertical vestibuloocular reflex tone, ${ }^{9}{ }^{10}$ as suggested for downbeat nystagmus (DBN). Alternatively, a mismatch in the neural coordinate systems of saccade generation and neural velocity-to-position integration due to deficiency of the latter might cause UBN, as has been suggested for DBN. ${ }^{11}$

GABAergic substances such as baclofen ${ }^{12}$ have been used to treat UBN and DBN, but with only moderate success. Recently 3,4-diaminopyridine ${ }^{13}$ and 4-aminopyridine $(4-\mathrm{AP})^{14}$ were shown to suppress DBN effectively. These potassium channel blockers are known to cancel the A current and the delayed rectifier, as well as other potassium channels. ${ }^{15}$ Animal experiments have recently shown that 4-AP increases the excitability of cerebellar Purkinje cells. ${ }^{16}$ Both drugs are thought to influence DBN by increasing the physiological inhibitory influence of the vestibulocerebellum on the vestibular nuclei. $^{13}{ }^{15}$ This prompted us to test the effects of 4-AP on UBN by measuring smooth pursuit and gaze holding with the search coil technique in a patient with UBN.

\section{METHODS}

A 22 year old man noted sudden onset of blurred vision, which he described as "running downward of visual images",
24 hours after hitting his head on a beam when suddenly standing up from a sitting position. Neurological examination six weeks later was normal except for UBN in gaze straight ahead (visual acuity: right eye 0.33 , left eye 0.25 ). UBN increased during convergence, and upward and lateral gaze to the left, and decreased in downward gaze. Upward smooth pursuit was impaired in the form of cogwheel movements. Psychophysical testing revealed a slight tilt of the subjective visual vertical to the right. Saccades were normal. Magnetic resonance imaging (MRI) (including high resolution MRI of the brainstem and cerebellum and fast echo planar diffusion weighted images), blood chemistry, and analysis of cerebrospinal fluid were also normal. Brainstem auditory evoked potentials on the left side were delayed for interpeak latency of waves III and V, suggesting a mesencephalic lesion. ${ }^{17}$ Thus, UBN in this patient might have been caused by a small lesion of the midbrain.

4-AP was first administered six weeks after the accident, the patient took $10 \mathrm{mg}$ 4-AP daily for eight weeks. The medication was discontinued in view of gradual recovery (visual acuity: both eyes 1.0).

\section{Eye movement recordings}

The patient gave his written informed consent for the recordings which had been approved by the local ethics committee of the Medical Faculty of the University of Munich.

Three dimensional eye movements were recorded six weeks after the accident, before and 90 minutes after ingestion of $10 \mathrm{mg} 4-\mathrm{AP}$, and at a follow up examination another nine weeks later but without medication. Dual search coils (Skalar, Delft, the Netherlands) on the left eye (after topical anaesthesia with oxybuprocain- $\mathrm{HCl}$ ) and on the forehead were used to determine eye and head positions from the voltage induced by three orthogonal magnetic fields (Remmel, Ashland, MA, USA). The signals were digitised with a 12 bit analogue-digital converter at a sampling rate of $1 \mathrm{kHz}$. The three dimensional position of the eye and the slow phase velocity of the nystagmus were evaluated in nine horizontal-vertical eye positions, with the patient sitting in an upright position as described elsewhere. ${ }^{11}$ Eye movements were recorded in the dark while showing a continuously visible or a flashed target (visible for $750 \mathrm{~ms}$ before and after the target jump, dark period $2.5 \mathrm{~s}$ ) to avoid visual interference by fixation of the target. Horizontal and vertical smooth pursuit was tested by having the patient follow a moving laser dot (size $0.1^{\circ}$; frequency $0.1667 \mathrm{~Hz}$, amplitude $\pm 18^{\circ}$ ) at the centre of a screen placed $140 \mathrm{~cm}$ in front of the subject. Gain values were determined by linear regression of slow phase velocity to target velocity for positive and negative target velocities separately.

Abbreviations: 4-AP, 4-aminopyridine; DBN, downbeat nystagmus; UBN, upbeat nystagmus 

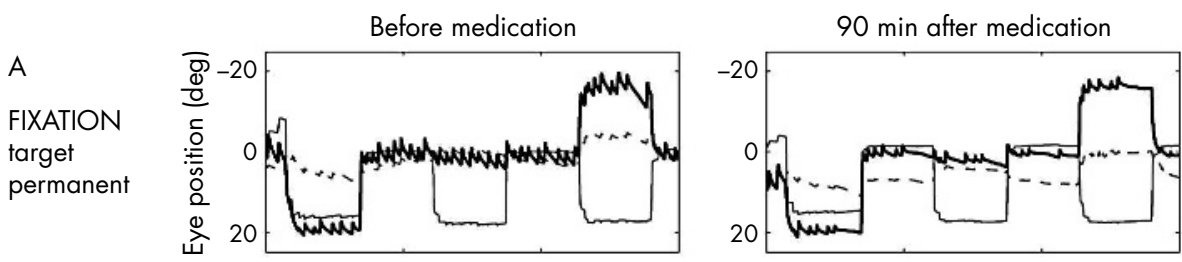

FIXATION

target

flashed

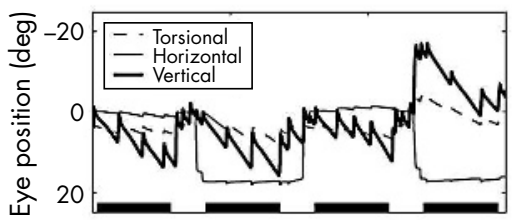

PURSUIT

target

permanent

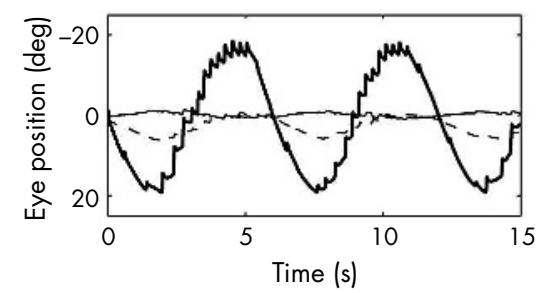

B

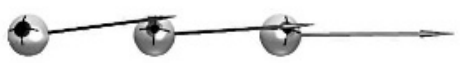

FIXATION

target

permanent
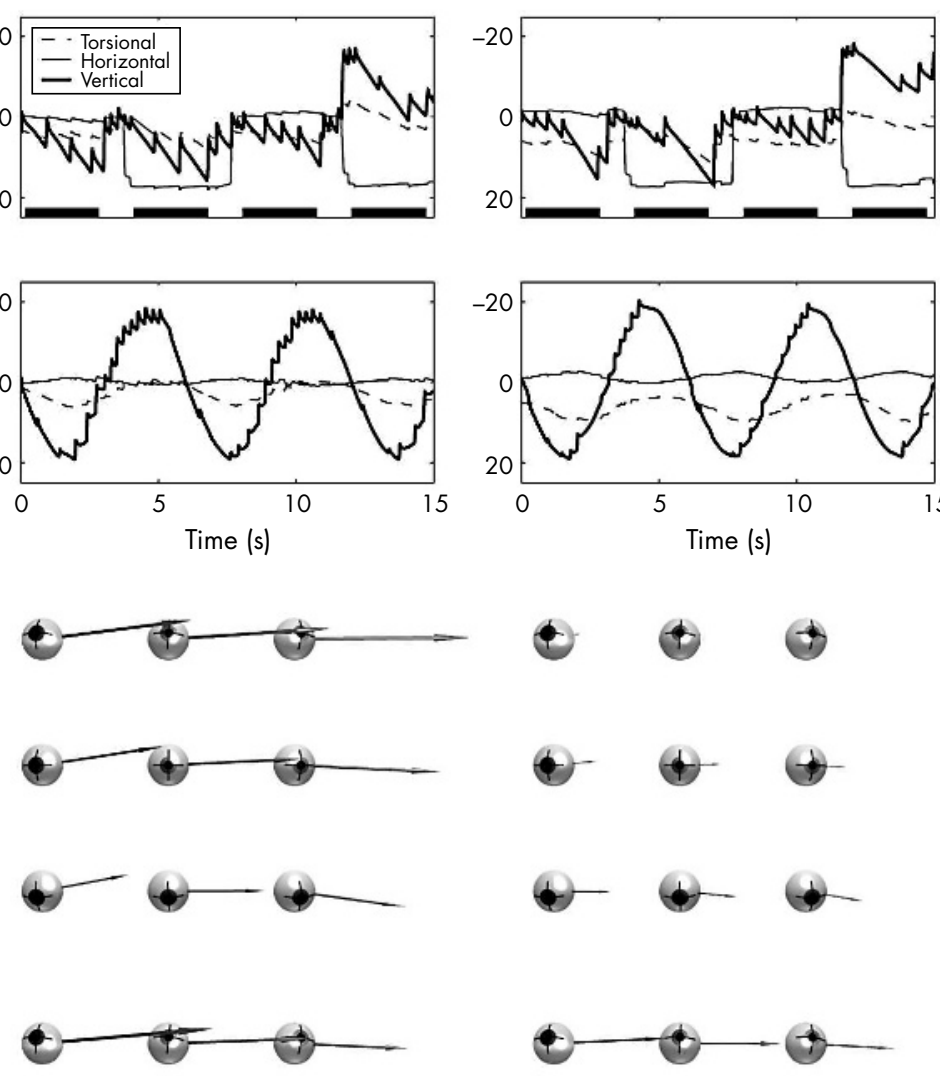

FIXATION

target

flashed
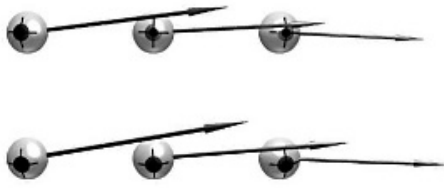

Figure 1 (A) Fifteen seconds of raw three dimensional eye position traces for fixation with visible target (upper panel), attempted fixation in darkness (middle panel, black horizontal bars indicate periods of darkness; note that fixation periods are longer than in the upper panel), and vertical smooth pursuit (lower panel). Left column: data before medication; right column: data 90 minutes after ingestion of $10 \mathrm{mg}$ 4-AP. The originally pronounced upbeat nystagmus (UBN) (upper panel, left) is nearly abolished after medication (upper panel, right) when the target was visible. The medication had no influence on nystagmus during attempted fixation in darkness (middle panel). Smooth pursuit before

medication was saccadic in the upward direction (lower panel, left) and improved significantly after medication (lower panel, right). (B) Eye position dependence of slow phase velocity of UBN for fixation with visible target (upper panel) and attempted fixation in darkness (lower panel). The eyeballs are shown for each of the required nine gaze directions. The arrows indicate the rotation axis of the eye-that is, a rightward pointing arrow indicates a downward driff. The length of the arrow is proportional to the drift velocity leyeball radius corresponds to $1.5 \mathrm{deg} / \mathrm{s}$ ). Left column: before medication; right column: 90 minutes after ingestion of 4-AP. Reversal of eye position dependence was observed before medication (left column): with permanent target, eye velocity was highest for upward gaze in accordance with Alexander's law, but in darkness, eye velocity increased for downward gaze.
Nine weeks later, the patient no longer had oscillopsia. The follow up experiment without medication showed a mean slow phase velocity of UBN of $3.0(0.1) \mathrm{deg} / \mathrm{s}$ (time constant $-18.2 \mathrm{~s})$.

Effects of 4-AP on UBN and eye position dependence in the dark with flashed target

4-AP had almost no effect on UBN during attempted fixation in darkness (fig 1A, middle panel; before medication: 12.0 (0.1) deg/s, after medication: $10.0(0.1) \mathrm{deg} / \mathrm{s})$. Vertical eye position dependence of slow phase velocity violated Alexander's law before and after medication (fig lB lower panel; before medication: $-9.3 \mathrm{~s}$, after medication: $-6.3 \mathrm{~s}$ ). Nine weeks later without medication, UBN in darkness was still larger than during fixation $(6.2(0.1) \mathrm{deg} / \mathrm{s}$, time constant $-22.1 \mathrm{~s}$ )

\section{Effects of 4-AP on smooth pursuit in UBN}

Vertical smooth pursuit was highly asymmetrical before medication (fig 1A, bottom panel; upward gain 0.38, time constant $-13.0 \mathrm{~s}$ ) - that is, UBN increased with downward gaze. 
downward gain 0.74). Upward smooth pursuit improved 90 minutes after medication (upward 0.89, downward 0.86). Horizontal smooth pursuit was normal before medication (rightward 0.98, leftward 0.95) and slightly increased afterwards. Nine weeks later, vertical smooth pursuit without medication was only slightly impaired (upward 0.82, downward 0.91).

\section{DISCUSSION}

The potassium channel blocker 4-AP substantially suppressed UBN in our patient during fixation in the light, but not in the dark, and improved upward vertical smooth pursuit. Accordingly, the patient felt relieved of distressing oscillopsia. The question arises as to how the medical effects are related to the pathomechanism of UBN. A cerebellar involvement is likely, since the ability of 4-AP to block several potassium currents-for example, the A current, the delayed rectifier, and calcium dependent potassium currents, ${ }^{18}$ leads to an increase of the excitability of cerebellar Purkinje cells. ${ }^{16}$

Eye position dependent UBN was smaller with a continuously visible fixation target than in the dark, even without medication. This suggests that visual input still had an impact on gaze holding (fig 1B, left column). 4-AP increased this influence so that UBN was nearly suppressed by visual input, but not in the dark (fig 1B, right column). We therefore assume that the concurrent improvement in smooth pursuit performance relied on the same visual mechanism mediated by 4 -AP. Hence, 4 -AP was unable to suppress UBN in darkness, but obviously activated pathways carrying visual information, which then could be used for UBN suppression in light.

Visual information for pursuit and nystagmus suppression reaches the Purkinje cells of the cerebellar flocculus and paraflocculus via the dorsolateral pontine nuclei and the mossy fibres, and additionally via the lateral terminal nuclei of the accessory optic system and the climbing fibres of the inferior olive. ${ }^{19}$ Since nystagmus suppression and upward pursuit were initially defective, it must be assumed that the lesion not only caused UBN in darkness, but also affected pathways carrying visual information for oculomotor control. It is unlikely that 4 -AP restored these pathways. Rather, we propose that 4-AP helps to activate parallel pathways that can take over the function of the lesioned structures. This parallel pathway may be strengthened by 4 -AP by increasing the excitability of cerebellar Purkinje cells. ${ }^{16}$ It may also evoke complex spikes in these cells similar to those elicited by climbing fibre stimulation. ${ }^{20}$

In summary, 4-AP may be an efficient agent for the treatment of UBN. Despite the striking effect of 4-AP in our patient, it remains to be tested in other patients with UBN due to various lesions to determine whether this compound is useful for all types of UBN with distressing oscillopsia.

\section{ACKNOWLEDGEMENTS}

We thank T Eggert for maintenance of the coil system, J Benson for copyediting the manuscript, and M Glaser for orthoptic examination of the patient.

\section{Authors' affiliations}

S Glasauer*, R Kalla*, U Büttner, M Strupp, T Brandt, Department of Neurology, University of Munich, Germany

This work was supported by the Deutsche Forschungsgemeinschaft (GL 342/1-1) and the Fritz-Thyssen-Stiffung.

Competing interests: none declared

*These authors contributed equally to the work.

Correspondence to: Dr S Glasaver, Department of Neurology, Klinikum Grosshadern, Marchioninistrasse 23, 81377 Munich, Germany; sglasaver@nefo.med.uni-muenchen.de

Received 14 May 2004

In revised form 6 July 2004

Accepted 7 July 2004

\section{REFERENCES}

1 Fisher A, Gresty M, Chambers B, et al. Primary position upbeating nystagmus. A variety of central positional nystagmus. Brain 1983;106:949-67.

2 Baloh RW, Yee RD. Spontaneous vertical nystagmus. Rev Neurol 1989; 145:527-32.

3 Munro NAR, Gaymard B, Rivaud S, et al. Upbeat nystagmus in a patient with a small medullary infarct. I Neurol Neurosurg Psychiatry 1993;56:1126-8.

4 Hirose G, Ogasawara T, Shirakawa T, et al. Primary position upbeat nystagmus due to unilateral medial medullary infarction. Ann Neurol 1998;43:403-6.

5 Büttner U, Helmchen C, Büttner-Ennever J. The localizing value of nystagmus in brainstem disorders. Neuro-ophthalmology 1998;15:283-90.

6 Janssen JC, Larner AJ, Morris $\mathrm{H}$, et al. Upbeat nystagmus: clinicoanatomical correlation. J Neurol Neurosurg Psychiatry 1998;65:380-1.

7 Kattah JC, Dagi TF. Compensatory head tilt in upbeating nystagmus. J Clin Neuroophthalmol 1990;10:27-31.

8 Ranalli PJ, Sharpe JA. Upbeat nystagmus and the ventral tegmental pathway of the upward vestibulo-ocular reflex. Neurology 1988;38:1329-30.

9 Nakada T, Remler MP. Primary position upbeat nystagmus. Another central vestibular nystagmus? J Clin Neuroophthalmol 1981;1:185-9.

10 Leigh RJ, Zee DS. The Neurology of Eye Movements, 3rd edn. Philadelphia: FA Davis 1999.

11 Glasaver S, Hoshi M, Kempermann U, et al. Three-dimensional eye position and slow phase velocity in humans with downbeat nystagmus. J Neurophysiol 2003;89:338-54.

12 Dieterich $M$, Straube A, Brandt T, et al. The effects of baclofen and cholinergic drugs on upbeat and downbeat nystagmus. J Neurol Neurosurg Psychiatry 1991; 54:627-32.

13 Strupp M, Schüler O, Krafczyk S, et al. Treatment of downbeat nystagmus with 3,4-diaminopyridine-a placebo-controlled study. Neurology 2003;61:165-70

14 Kalla R, Glasauer S, Schautzer F, et al. 4-aminopyridine improves downbeat nystagmus, smooth pursuit, and VOR gain. Neurology 2004;62:1228-9

15 Hille B. lonic channels of excitable membranes, 3rd edn. Sunderland, MA: Sinaver Associates, 2001

16 Etzion Y, Grossman Y. Highly 4-aminopyridine sensitive delayed rectifier current modulates the excitability of guinea pig cerebellar Purkinje cells. Exp Brain Res 2001;139:419-25.

17 Legatt AD. Mechanisms of intraoperative brainstem auditory evoked potential changes. J Clin Neurophysiol 2002;19:396-408.

18 Leigh RJ, Tomsak RL. Drug treatments for eye movement disorders. J Neurol Neurosurg Psychiatry 2003;74:1-4.

19 Hirata Y, Highstein SM. Acute adaptation of the vestibuloocular reflex: Signal processing by floccular and ventral parafloccular Purkinje cells. J Neurophysiol 2001;85:2267-88.

20 Cavelier P, Pouille F, Desplantez T, et al. Control of the propagation of dendritic low-threshold $\mathrm{Ca}(2+)$ spikes in Purkinje cells from rat cerebellar slice cultures. J Physiol 2002;540:57-72. 